\title{
Combining Indolizines and Isatins via Brønsted-Acid catalyzed Friedel- Crafts Alkylation in Water
}

\author{
Bruno B. Guidotti ${ }^{\S}$, Thiago S. Silva ${ }^{\S}$, José T. M. Correia ${ }^{\dagger}$, Fernando Coelho* \\ Laboratory of Synthesis of Natural Products and Drugs - Institute of Chemistry, University of Campinas, Rua Monteiro \\ Lobato, S/N, 13083-970, Campinas, São Paulo, Brazil.
}

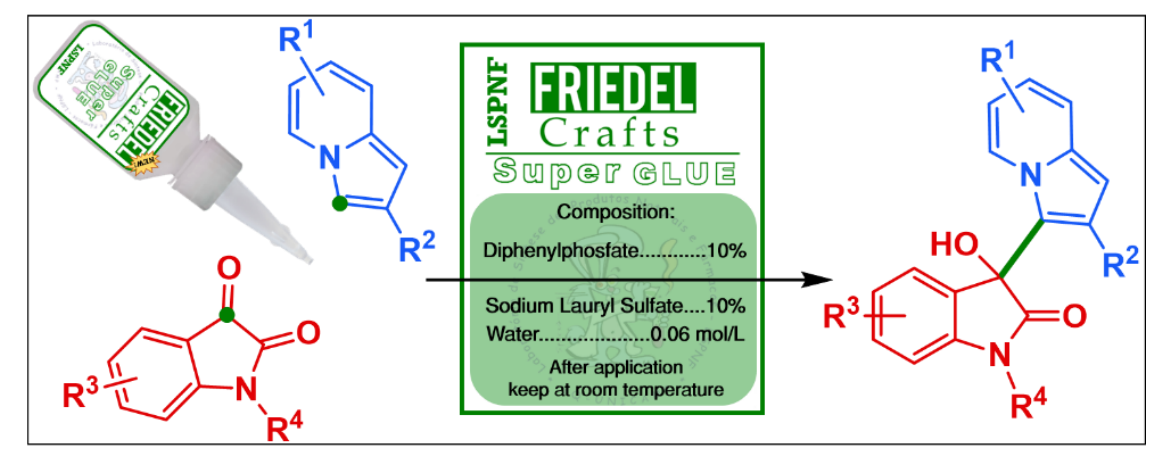

\begin{abstract}
The controlled mono-addition of indolizines to isatins under very mild conditions is described. The reaction occurs in water using diphenylphosphate (DPP) as catalyst and is dramatically accelerated by adding a surfactant (sodium dodecyl sulfate SDS). Using this methodology, 19 new 3-hydroxy-3-indolizinyl-2-oxindoles scaffolds were synthesized (up to >99\% yield). Notably, in organic solvents only bis-addition products were observed, in poor yields and in prolonged times. The very low solubility of the mono-addition product in water was determinant for the observed selectivity .
\end{abstract}

We are surrounded by a myriad of natural and synthetical heterocyclic molecules, widely found in food, materials, cosmetics, agrochemicals, drugs and in living beings. ${ }^{(1)}$ One important class of heterocycles is the indolizine which has drawn attention in recent years due its presence in the core of compounds with a wide range of biological activities like antineoplastic, ${ }^{(2)}$ antibacterial and antifungal, ${ }^{(3)}$ anti-HIV, ${ }^{(4)}$ antihistaminic, ${ }^{(5)}$ analgesic and anti-inflammatory, ${ }^{(6)}$ anticonvulsant ${ }^{(7)}$ and central nervous system depressant $\operatorname{activities}^{(7),(8)}$, and in photophysical applications as biosensors for reactive oxygen species (ROS) and lipid droplets (LD). ${ }^{(9)}$

Many syntheses were accomplished over the years owing the relevance of the indolizine core, ${ }^{(10)}$ however its post-functionalization is still an underexplored field. Most of the reports on post-functionalization of indolizines relies on the use of transition-metal catalysis in coupling reactions, ${ }^{(11)}$ metalation reactions ${ }^{(12)}$ or in Lewis acid catalyzed Friedel-Crafts(FC)-type additions. ${ }^{(13)}$ Examples of metalfree methodologies for indolizine functionalization are much more scarce, ${ }^{(14)}$ nevertheless, in recent years our group have been successful in the development of these methodologies, reporting the use of indolizines as nucleophilic partners in 1,4-addition-type FC alkylations with $\alpha, \beta$-unsaturated olefins. ${ }^{(15)}$

Seeking for other substrates that could act as electrophile on FC reactions with indolizines, we envisioned that isatins could be a proper choice (Scheme 1). Isatins can undergo nucleophilic attacks on C-3 to yield 3-hydroxy-2-oxindoles derivatives, which are known as nucleus of natural products and bioactive molecules. ${ }^{(16)}$ Furthermore, there are plenty of methodologies for the 1,2 -additiontype FC alkylation between isatins and heteroarenes - such as pyrroles, ${ }^{(17)}$ and indoles ${ }^{(18)}$ - or electron-rich arenes, ${ }^{(19)}$ but to the best of our knowledge, the use of indolizines for this transformation remains unknown. 
Inspired by our previous success in FC alkylation between indolizines and enones under Brønsted acid (BA) catalysis, ${ }^{(15)}$ we speculated if diphenyl phosphate (DPP) would be a suitable catalyst for isatin activation. Furthermore, the use of acid catalysis in nucleophilic 1,2 additions to carbonyl compounds to obtain mono alkylated FC adducts is usually avoided due to the tendency of obtained alcohols to form stabilized carbocations that reacts with another nucleophile molecule to afford bis-substituted FC adducts. ${ }^{(20)}$ We describe herein our efforts to developed a FC reaction between indolizines and isatins that exclusively affords monoaddition products even under acid catalysis (Scheme 1).

\section{Scheme 1. FC alkylation of carbonyl compounds under BA catalysis.}

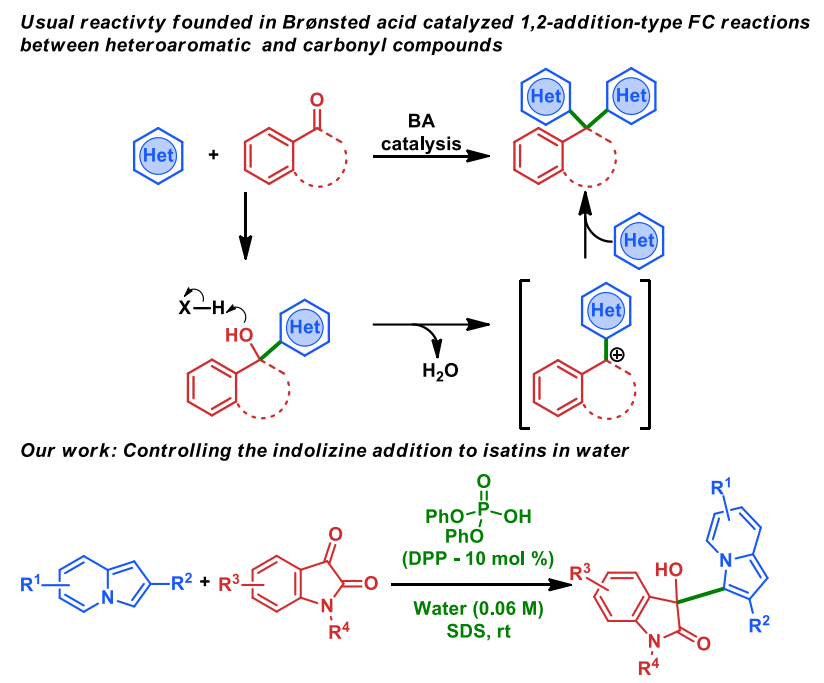

We began our investigations by studding the reaction between methyl 2-indolizinecarboxylate 1a and the N-methyl-isatin $\mathbf{2 a}$ in set of organic solvents (see Table S1 in the SI). At first, 2a (1 equiv) was exposed to excess of $1 \mathbf{a}$ (2.3 equiv) in the presence of DPP (10 mol \%) and benzene $(0.06 \mathrm{M})$ at room temperature. The reaction took place in 96 hours and only the bis-addition adduct 4 aa was obtained in $40 \%$ yield (Table 1, entry 1). Further solvent screening proved to be ineffective for reaction improvement (Table S1), and only 4aa was obtained in all cases in poor to moderate yields. The best result was achieved using 1,2-DCE as solvent, 61\% yield in 96 hours (Table 1 , entry 2 ).

Considering the possibilities of organic solvents being exhausted (Table S1), the last solvent tested was water (Table 1, entries 3 11). To our surprise and delight, the completely heterogeneous reaction furnished the mono-addition adduct $\mathbf{3 a a}$ in $95 \%$ yield as a single product and in a shorter reaction time - $65 \mathrm{~h}$ (entry 3). The reaction stoichiometry and catalytic loading were further investigated. Reducing the catalyst load to $5 \mathrm{~mol} \%$, led to a significant decrease in the reaction conversion (entry 4 ). Likewise, an attempt to set $1 \mathbf{a}$ as the limiting reagent led to $41 \%$ conversion (entry 5 ). Prolonging the reaction time for 7 days, leads to a slightly decrease of 3aa yield to $88 \%$ and 4 aa also could be isolated in $5 \%$ yield (entry 6).

Aiming to enhance the solubility of components in water, in order to accelerate the transformation without compromise the selectivity, sodium dodecyl sulfate (SDS) was used as additive (Table 1, entries 7-12). ${ }^{(21)}$ Fortunately, this additive was capable of dramatically reduce the reaction time to $16 \mathrm{~h}$, maintaining a high conversion rate (93\%) to 3aa (Table 1, entry 7). Optimal conditions were then obtained when we reduced the amount of 1a to 1.2 equivalents in the presence of SDS (10 mol \%, $6 \mathrm{mM}$ ), affording 3aa with conversion of $91 \%$ in $16 \mathrm{~h}$ (entry 8). Noteworthy, in the best conditions (entries 6 and 7 ) the surfactant concentration is a small value below of the SDS critical micellar concentration (CMC) of $\sim 8.2 \mathrm{mM},{ }^{(22)}$ a serendipitous finding. Decreasing the amount of 1a to 1.0 equiv led to a significant lowering of conversion rate (entry 9). Increasing the reaction molarity (Entries 10 and 11 ), led to observation of a complex mixture of products what could be correlated with the SDS concentration values in these cases, $12 \mathrm{mM}$ and $24 \mathrm{mM}$, were above the CMC value. ${ }^{(23)}$ Increasing the reaction temperature to $50{ }^{\circ} \mathrm{C}$ was detrimental to the process and the product was obtained in a lower conversion accompanied by side products (entry 12). 


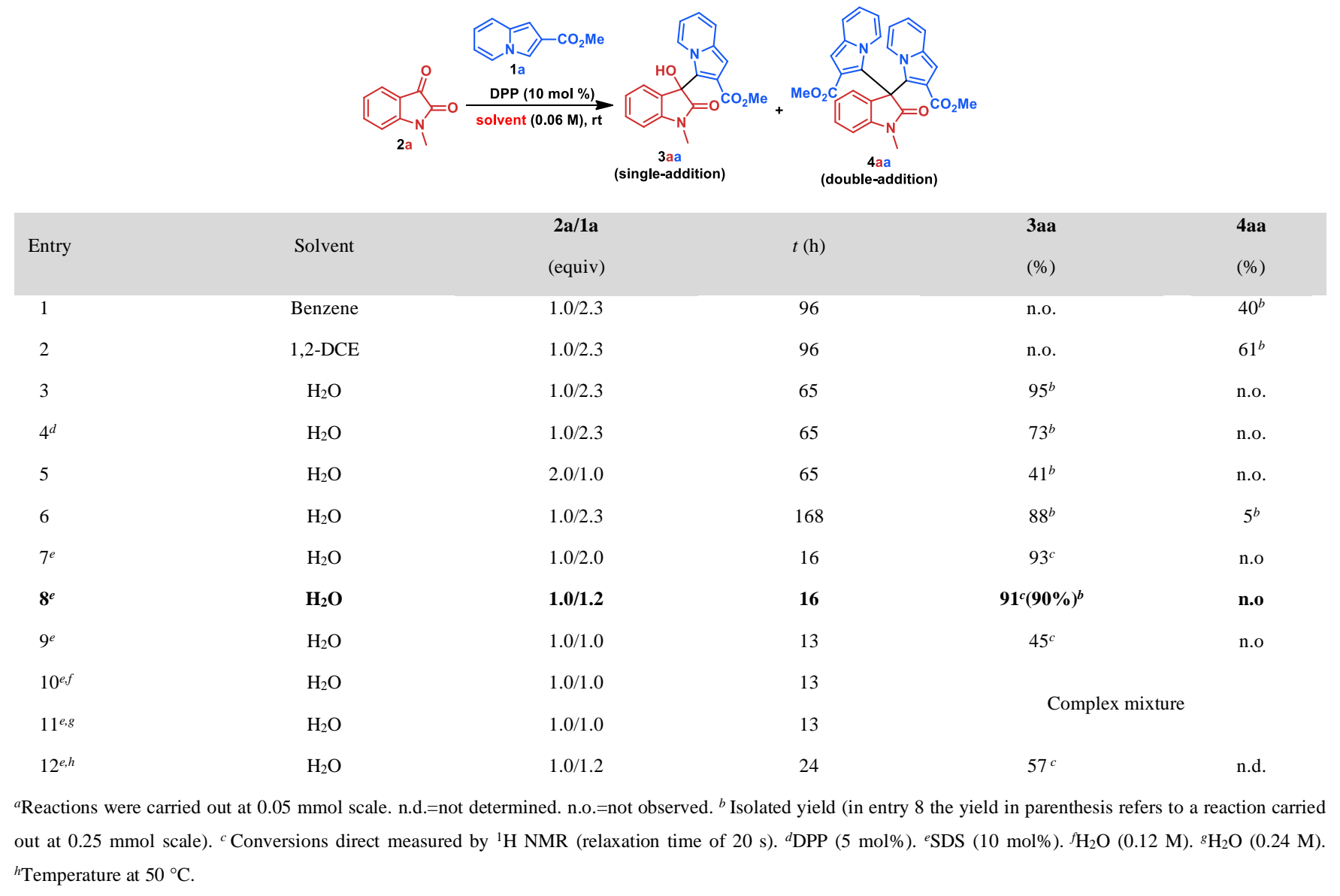

With the optimized conditions in hands, the scope and limitations of the methodology were evaluated. First, structurally diverse isatins $\mathbf{2 b}-\mathbf{2} \mathbf{m}$ were tested in the presence of $\mathbf{1 a}$ (Scheme 2). Isatins with electron-donor groups in the C-5 position yielded the monoaddition adducts $\mathbf{3 b a}$ (74\%), 3ca (22\%) and 3da (12\%) in a much less efficient way comparing to the model 3aa, suggesting that electron-donor groups strongly disfavor the reaction. C-5 halogenated isatins $\mathbf{2 e - 2 h}$ showed that the efficiency of the reaction increases with the electronegativity, delivering $\mathbf{3 e a}(5-\mathrm{I})$ in $19 \mathrm{~h}$ and 55\% yield, whereas $\mathbf{3 h a}(5-\mathrm{F})$ was obtained in $7 \mathrm{~h}$ and $90 \%$ yield. However, this effect was not observed for C-7 halogenated isatins $\mathbf{2 i}(7-\mathrm{Br})$ and $\mathbf{2} \mathbf{j}(7-\mathrm{Cl})$, which afforded $\mathbf{3 i a}$ in $91 \%$ yield and $\mathbf{3 j a}$ in $72 \%$ yield $(7-\mathrm{Cl})$ both in 7 hours. The 5-7-dichloro- $N$-methyl-isatin $2 \mathbf{k}$ furnished the FC adducts $3 \mathbf{k a}$ in $96 \%$ yield, better yield comparing with the mono-chloride derivatives (3ga, $\mathbf{3 j a}$ and $\mathbf{3 l a}$ ). Nitro-substituted isatin $\mathbf{2} \mathbf{m}$, whose we expected to give an excellent yield due the activation of the C-3 position by the presence of a strong electro-withdrawing group, afforded 3 ma in moderate $77 \%$ yield, what was attributed to byproducts formation, specially the bis-addition adduct (not isolated).

Next, we investigated the reactivity between indolizines 1a-j and isatin 2a (Scheme 2). Substitution at the indolizine C-2 position for a nitrile group (1c) furnished the adduct $\mathbf{3 a c}$ in poor yield (15\%), and the hydrolyzed indolizine ester $\mathbf{1 b}$ did not react under reaction conditions. C-8 substituted indolizines $\mathbf{1 d}$ and $\mathbf{1 e}$ also did not reacted and after $36 \mathrm{~h}$, almost all isatin $\mathbf{2 a}$ was recovered in both cases. Indolizines substituted at C-6 delivered FC adducts in moderated yields, 43\% to 50\%, with methyl group (3ag) and halogens atoms (3ah and 3ai). Despite that, reaction with 7-methyl substituted indolizine 1f and, unexpectedly, with 5-Br substituted indolizine $\mathbf{1 j}$ presented excellent yields. 3af was delivered in $>99 \%$ yield in only $4 \mathrm{~h}$ suggesting that this group can favor the nucleophilic attack by enhancement of electron density at C-3 indolizine carbon. 3aj was formed in 91\% yield but required 3 days of reaction, and, although we did not expect that the presence of an electron-withdrawing group in the nucleophile $\mathbf{1} \mathbf{j}$ could be beneficial 
for reaction yield, the increase of product steric hindrance due the position of bromine atom in 1aj could reduce parallel reactions like a second addition or even a retro-FC reaction.

\section{Scheme 2. Scope of FC reaction between Isatins (2b-n) and indolizines (1b-1k) ${ }^{\mathrm{a}}$}

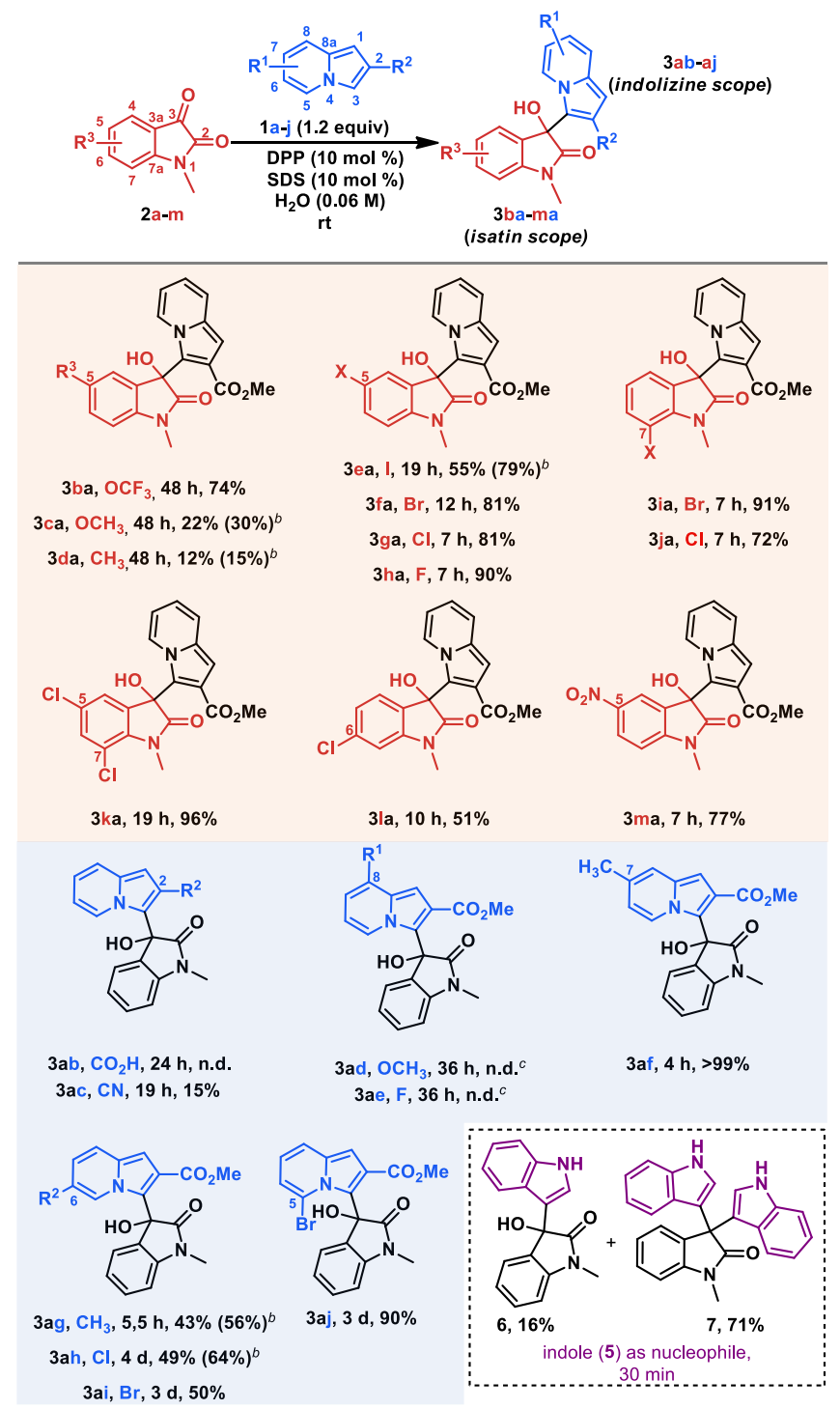

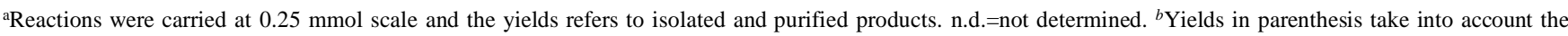
recovery of $\mathbf{2}$. ${ }^{c}$ Recovery of $>98 \%$ of $\mathbf{2 a}$

In contrast with the controlled indolizine 1,2-additions, indole (5) addition to isatin 2a under optimized conditions favored majoritary the dialkylation product 7 , obtained in $71 \%$ yield together with the mono-FC adduct 6 (16\% yield). The reaction was considerably faster $(30 \mathrm{~min})$ than those with indolizine analogues (Scheme 1, dashed box). The observed differences in product distribution, served as a hint that reaction selectivity was not only associated with the solvent choice.

Aiming explore the reactivity of the FC adducts in the presence of other nucleophiles, we reacted 3aa with indole under Brønsted acid catalysis in an organic solvent (DCE) expecting to obtain unsymmetrical 3,3' disubstituted oxindole 8 (Scheme 4). ${ }^{\text {(24) }}$ Unexpectedly, after 8 hours, disubstituted indole 7 was obtained in quantitative yield, what suggested two possible scenarios: 1) the indole in $\mathbf{7}$ induced an indolizine retro-FC reaction, generating an alkylidene intermediate that was attacked by a second indole 
molecule ; 2) a Brønsted acid induced a retro-FC reaction of adduct 3aa, followed by indole bis-addition to isatin. Control experiment using 3-hydroxy-3-indole-2-oxaindole $\mathbf{6}$ and indolizine 1a as nucleophile, gave the desired compound 5 in $84 \%$ yield in 3 hours, which excluded the first scenario. Next, a stability test in which 3aa was mixed with DPP (10 mol\%) in 1,2-DCE in the absence of a nucleophile revealed its progressive degradation, with concomitant formation of free isatin $\mathbf{2 a}$ and indolizine 1a alongside with the bis-addition product 4aa (see Figure S3 in the SI).

\section{Scheme 3. Attempted of unsymmetrical disubstituted 2-oxindoles synthesis from 3aa and control experiments ${ }^{\mathrm{a}}$}

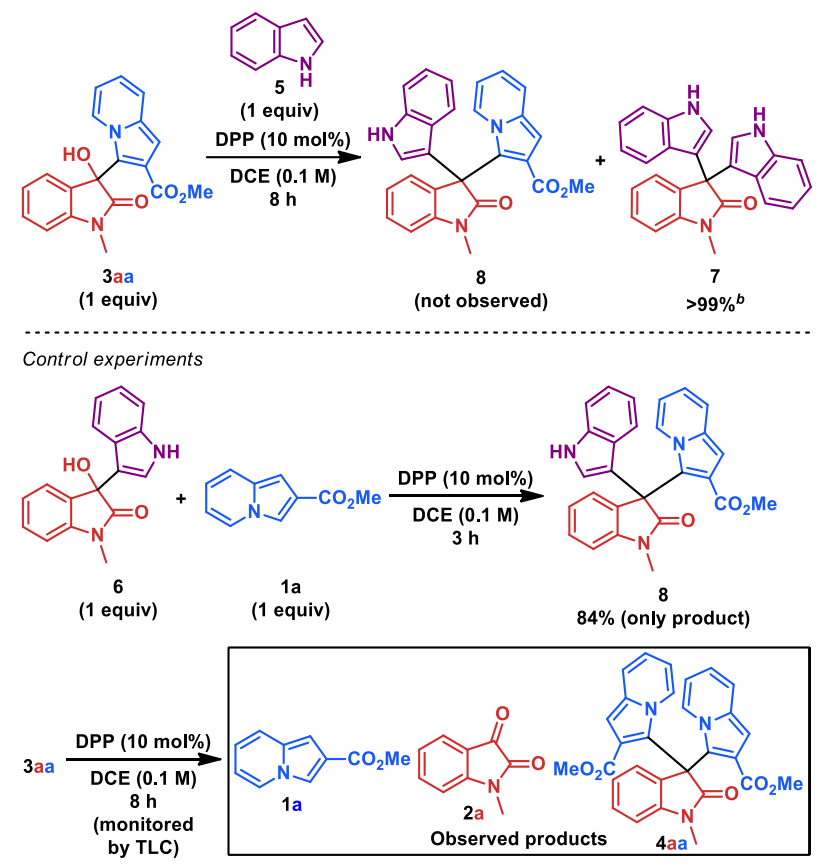

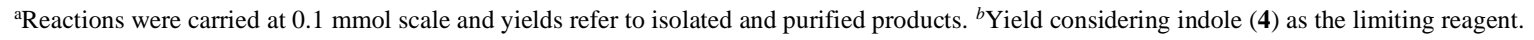

The previous observations suggests that there is a dynamic equilibrium between the first indolizine addition and a retro-FC reaction, and, in organic medium, the indolizine mono-addition adducts tend to suffer a retro-FC more rapidly than the addition of a second nucleophile (Scheme 4). This would explain the low yields and long reaction times observed in reactions between indolizine 1a and isatin 2a in organic solvents (Table S1). We postulated that this equilibrium is hampered under aqueous condition due the insolubility of reactants and the mono alkylated products $\mathbf{3}$, explaining their stability in water.

The fact that a simple solvent shifting made a complete change in the selectivity of the reaction is very intriguing. It is plausible that the very low solubility of the components in water could lowered the reaction rate disfavoring a second addition of 1a (Scheme 4), what is in accordance with the previous result (entry 6 of table 1), in which the bis-addition adduct 4aa was observed in low yield (5\%) after extending the reaction time to $168 \mathrm{~h}$ (7 days), causing a little erosion in the yield of 3aa. This hypothesis also explains the fail attempts in increase reaction molarity maintaining the same amount of surfactant (Table 1, entries 10 and 11), ${ }^{(23)}$ exhibiting the thin line between a positive surfactant effect on the reaction acceleration and a detrimental one. Although we cannot completely rule out the reversibility of water dissociation, dislocating the equilibrium in favor of the mono-addition product, as a factor for the observed reactivity, carbocation substitutions reactions in water are reported in literature, ${ }^{(20)}$ and also observed under our conditions (Scheme 1, 2m and 6). 


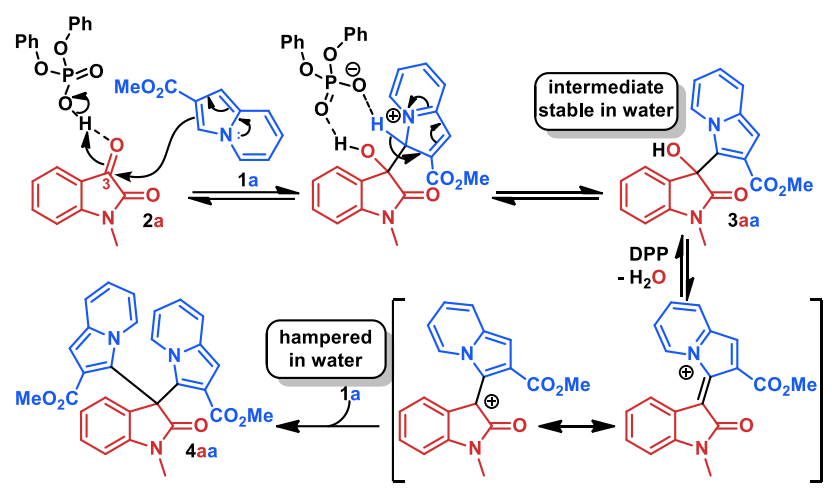

In summary, we disclosed a FC alkylation between indolizines and isatins under Brønsted acid catalysis. Noteworthy, this is the first report of an organocatalyzed 1,2 FC addition using the indolizine nucleus. This methodology is very mild, and its selectivity strongly depends on the solvent used. While organic solvents gave exclusively dialkylated adducts in poor yields and long reaction times, employment of water as the solvent allowed the obtention of acid labile mono-substituted FC adducts in improved yields and in shorter reaction times when a surfactant was present. Theoretical studies to have new insights about the reactivity of the FC adducts are currently underway along with efforts for the development of an asymmetric variation.

\section{ASSOCIATED CONTENT}

\section{AUTHOR INFORMATION}

\section{Corresponding Author}

*E-mail: fcoelho@unicamp.br

\section{ORCID}

Fernando Coelho: 0000-0003-1800-1549

\section{Present Addresses}

+Centre of Excellence for Research in Sustainable Chemistry (CERSusChem), Department of Chemistry, Federal University of São Carlos, São Carlos, São Paulo, Brazil 13565-905

\section{Author Contributions}

The manuscript was written through contributions of all authors./ All authors have given approval to the final version of the manuscript. $\S$ These authors contributed equally to this work.

Notes

The authors declare no competing financial interest.

\section{ACKNOWLEDGMENT}

This study was financed, in part, by the Coordenacão de Aperfeiçoamento de Pessoal de Nível Superior-Brasil (CAPES)-Finance Code 001. F.C. thanks also the Brazilian National Council for Science and Development (CNPq) for the research fellowship (process nos. 307840/2014- 
0 and 301330/2018-2) and FAPESP (process nos. 2013/07600-3 and 2018/02611-0). B.B.G. and T.S.S. thank CAPES for fellowships. J.T.M.C thanks FAPESP (process 2012/21809-0) for the fellowship.

\section{REFERENCES}

(1) (a) Progress in Heterocyclic Chemistry; Gribble, G. W., Joule, J. A., Eds.; Elsevier: Oxford, 2003-2016; Vols. 15-28 (b) Quin L. D.; John Tyrell, J.A. Fundamentals of heterocyclic chemistry: importance in nature and in the synthesis of pharmaceuticals. John Wiley \& Sons: New Jersey, 2010. (c)Vitaku, E.; Smith, D. T.; Njardarson, J. T. Analysis of the Structural Diversity, Substitution Patterns, and Frequency of Nitrogen Heterocycles among U.S. FDA Approved Pharmaceuticals. J. Med. Chem. 2014, 57, 10257-10274.

(2) De, A. U.; Saha, B. P. Indolizines II: Search for Potential Oral Hypoglycemic Agents. J. Pharm. Sci. 1975, 64, $249-252$.

(3) Darwish, E. S. Facile Synthesis of Heterocycles via 2-Picolinium Bromide and Antimicrobial Activities of the Products. Molecules 2008, 13, 1066-1078.

(4) Huang, W.; Zuo, T.; Luo, X.; Jin, H.; Liu, Z.; Yang, Z.; Yu, X.; Zhang, L.; Zhang, L. Indolizine Derivatives as HIV-1 VIF-ElonginC Interaction Inhibitors. Chem. Biol. Drug Des. 2013, 81, 730-741.

(5) Chai, W.; Breitenbucher, J. G.; Kwok, A.; Li, X.; Wong, V.; Carruthers, N. I.; Lovenberg, T. W.; Mazur, C.; Wilson, S. J.; Axe, F. U.; et al. NonImidazole Heterocyclic Histamine H3 Receptor Antagonists. Bioorg. Med. Chem. Lett. 2003, 13, 1767-1770.

(6) Kallay, K. R.; Doerge, R. F. P-Substituted 1,2-Diphenylindolizines as Anti-Inflammatory Agents. J. Pharm. Sci. 1972, 61, 949-951.

(7) Dawood, K. M.; Abdel-Gawad, H.; Ellithey, M.; Mohamed, H. A.; Hegazi, B. Synthesis, Anticonvulsant, and Anti-Inflammatory Activities of Some New Benzofuran-Based Heterocycles. Arch. Pharm. (Weinheim). 2006, 339, 133-140.

(8) Harrell, W. B.; Doerge, R. F. Mannich Bases from 2-Phenylindolizines I. 3-Alkyl-1-Dialkylaminomethyl Derivatives. J. Pharm. Sci. 1967, 56, 225-228.

(9) Kim, E.; Lee, Y.; Lee, S.; Park, S. B. Discovery, Understanding, and Bioapplication of Organic Fluorophore: A Case Study with an Indolizine-Based Novel Fluorophore, Seoul-Fluor. Acc. Chem. Res. 2015, 48, 538-547.

(10) (a) de Souza, C. R.; Gonçalves, A. C.; Amaral, M. F. Z. J.; Dos Santos, A. A.; Clososki, G. C. Recent Synthetic Developments and Reactivity of Aromatic Indolizines. Targets Heterocycl. Syst. 2016, 20, 365-392; (b) Sadowski, B.; Klajn, J.; Gryko, D. T. Recent Advances in the Synthesis of Indolizines and Their $\pi$-Expanded Analogues. Organic and Biomolecular Chemistry. 2016, pp 7804-7828; (c) Singh, G. S.; Mmatli, E. E. Recent Progress in Synthesis and Bioactivity Studies of Indolizines. Eur. J. Med. Chem. 2011, 46, 5237-5257.

(11) (a) Park, C.-H.; Ryabova, V.; Seregin, I. V.; Sromek, A. W.; Gevorgyan, V. Palladium-Catalyzed Arylation and Heteroarylation of Indolizines. Org. Lett. 2004, 6, 1159-1162. (b) Yang, Y.; Cheng, K.; Zhang, Y. Highly Regioselective Palladium-Catalyzed Oxidative Coupling of Indolizines and Vinylarenes via C-H Bond Cleavage. Org. Lett. 2009, 11, 5606-5609. (c) Lu, M.; Shi, F.; Ji, M.; Kan, Y.; Hu, H. Palladium Catalyzed C-H Olefination of Indolizines at the 1-Position with Molecular Oxygen as the Terminal Oxidant. Asian J. Org. Chem. 2019, 8, 1555-1560. (d) Kahar, N. M.; Nabar, K. U.; Jadhav, P. P.; Dawande, S. G. Rhodium(II)-Catalyzed Highly Stereoselective C3 Functionalization of Indolizines with N-Sulfonyl-1,2,3-Triazoles. Asian J. Org. Chem. 2019, 8, 79-82. (e) Feng, X.; Tian, J.; Sun, Y.; Hu, H.; Lu, M.; Kan, Y.; Fang, D.; Wang, C. Weakly Coordinating Group Directed Rhodium-Catalyzed Unconventional Site-Selective C-H Olefination of Indolizines at the 8-Position. Chinese Chem. Lett. 2020.

(12) (a) Amaral, M. F. Z. J.; Baumgartner, A. A.; Vessecchi, R.; Clososki, G. C. Directed Metalation of 1-Ester-Substituted Indolizines: Base/ElectrophileControlled Regioselective Functionalization. Org. Lett. 2015, 17, 238-241. (b) Bertallo, C. R. d. S.; Arroio, T. R.; Toledo, M. F. Z. J.; Sadler, S. A.; Vessecchi, R.; Steel, P. G.; Clososki, G. C. C-H Activation/ Metalation Approaches for the Synthesis of Indolizine Derivatives. Eur. J. Org. Chem. 2019, 2019, $5205-5213$.

(13) (a) Shao-hong, X. Iron-Catalysed C-3 Functionalisation of Indolizines via C - H Bond Cleavage. J. Chem. Res. 2012, 3, 441-443. (b) Matviiuk, T.; Mori, G.; Lherbet, C.; Rodri-guez, F.; Pasca, M. R.; Gorichko, M.; Guidetti, B.; Voitenko, Z.; Baltas, M. Synthesis of 3- Heteryl Substituted Pyrrolidine-2,5Diones via Catalytic Michael Reaction and Evalua-tion of Their Inhibitory Activity against InhA and Mycobacterium Tuberculosis. Eur. J. Med. Chem. 2014, 71, 46-52. (c) Jung, Y.; Kim, I. C3 Functionalization of Indolizines via In(III)-Catalyzed Three-Component Reaction. Org. Biomol. Chem. 2015, 13, 1098610994. (d) Yang, L.; Pu, X.; Niu, D.; Fu, Z.; Zhang, X. Copper-Catalyzed Asymmetric Propargylation of Indolizines. Org. Lett. 2019, $21,8553-8557$.

(14) (a) Gao, S.; Xu, X.; Yuan, Z.; Zhou, H.; Yao, H.; Lin, A. 1,6-Addition Arylation of Para-Quinone Methides: An Approach to Unsymmetrical Triarylmethanes. European J. Org. Chem. 2016, 2016, 3006-3012. (b) Albaladejo, M. J.; Gonzalez-Soria, M. J.; Alonso, F. Metal-Free Remote-Site C-H Alkenylation: Regio- and Diastereoselective Synthesis of Solvatochromic Dyes. Green Chem. 2018, 20, 701-712. (c) Liang, Y.; Teng, L.; Wang, Y.; He, Q.; Cao, H. A Visible-LightInduced Intermolecular [3 + 2] Alkenylation-Cyclization Strategy: Metal-Free Construction of Pyrrolo[2,1,5-Cd] Indolizine Rings. Green Chem. 2019, 21, 4025-4029.

(15) (a) Correia, J. T. M.; List, B.; Coelho, F. Catalytic Asymmetric Conjugate Addition of Indolizines to $\alpha, \beta$-Unsaturated Ketones. Angew. Chemie - Int. Ed. 2017, 56, 7967-7970. (b) Silva, T. S.; Zeoly, L. A.; Coelho, F. Catalyst-Free Conjugate Addition of Indolizines to In Situ -Generated Oxidized MoritaBaylis-Hillman Adducts. J. Org. Chem. 2020, 85, 5438-5448.

(16) (a) Yu, B.; Xing, H.; Yu, D.-Q.; Liu, H.-M. Catalytic Asymmetric Synthesis of Biologically Important 3-Hydroxyoxindoles: An Update. Beilstein J. Org. Chem. 2016, 12, 1000-1039; (b) Yu, B.; Yu, D.-Q.; Liu, H.-M. Spirooxindoles: Promising Scaffolds for Anticancer Agents. Eur. J. Med. Chem. 2015, 
97, 673-698; (c) Yu, B.; Yu, Z.; Qi, P.-P.; Yu, D.-Q.; Liu, H.-M. Discovery of Orally Active Anticancer Candidate CFI-400945 Derived from Biologically Promising Spirooxindoles: Success and Challenges. Eur. J. Med. Chem. 2015, 95, 35-40; (d) Hong, L.; Wang, R. Recent Advances in Asymmetric Organocatalytic Construction of 3,3'-Spirocyclic Oxindoles. Adv. Synth. Catal. 2013, 355, 1023-1052. (e) Rubal, J. J.; Moreno-Dorado, F. J.; Guerra, F. M.; Jorge, Z. D.; del Carmen Galán, M.; Salido, G. M.; Christensen, S. B.; Søhoel, H.; Massanet, G. M. A Phenylpropanoid, a Slovenolide, Two SulphurContaining Germacranes and Ca2+-ATPase Inhibitors from Thapsia Villosa. Planta Med 2010, 76, 284-290; (f) Peddibhotla, S. 3-Substituted-3-Hydroxy-2Oxindole, an Emerging New Scaffold for Drug Discovery with Potential Anti-Cancer and Other Biological Activities. Current Bioactive Compounds. 2009, 20-38; (g) Galliford, C. V.; Scheidt, K. A. Pyrrolidinyl-Spirooxindole Natural Products as Inspirations for the Development of Potential Therapeutic Agents. Angew. Chemie Int. Ed. 2007, 46, 8748-8758.

(17) (a) Gao, Z.; Zhang, J.; Yang, H.; Jiang, G. Brønsted Acid-Promoted Friedel-Crafts Alkylation/Cyclization of (7-Hydroxynaphthalenyl)Pyrrole or (2Hydroxyphenyl)Pyrroles with Isatins for the Construction of Pyrrolospirooxindole Derivatives. J. Org. Chem. 2018, 83, 11407-11414; (b) Li, C.; Guo, F.; Xu, K.; Zhang, S.; Hu, Y.; Zha, Z.; Wang, Z. Copper-Catalyzed Enantioselective Friedel-Crafts Alkylation of Pyrrole with Isatins. Org. Lett. 2014, 16, 31923195; (c) Gutierrez, E. G.; Wong, C. J.; Sahin, A. H.; Franz, A. K. Enantioselective and Regioselective Indium(III)-Catalyzed Addition of Pyrroles to Isatins. Org. Lett. 2011, 13, 5754-5757.

(18) (a) Gu, Y.-C.; Hu, R.-M.; Li, M.-M.; Xu, D.-Z. Iron-Containing Ionic Liquid as an Efficient and Recyclable Catalyst for the Synthesis of C3-Substituted Indole Derivatives. Appl. Organomet. Chem. 2019, 33, e4782; (b) Dalal, K. S.; Wagh, Y. B.; Tayade, Y. A.; Dalal, D. S.; Chaudhari, B. L. Hen Egg White Lysozyme Catalyzed Efficient Synthesis of 3-Indolyl-3-Hydroxy Oxindole in Aqueous Ethanol. Catal. Letters 2018, 148, 3335-3341; (c) Tong, J.; Huang, L.-S.; Xu, D.-Z. An Efficient Friedel-Crafts Alkylation for the Synthesis of 3-Indolyl-3-Hydroxy Oxindoles and Unsymmetrical 3,3-Diaryl Oxindoles Catalyzed by Dabco-Based Ionic Liquids in Water. New J. Chem. 2017, 41, 3966-3974; (d) Deng, J.; Zhang, S.; Ding, P.; Jiang, H.; Wang, W.; Li, J. Facile Creation of 3-Indolyl-3-Hydroxy-2-Oxindoles by an Organocatalytic Enantioselective Friedel-Crafts Reaction of Indoles with Isatins. Adv. Synth. Catal. 2010, 352, 833-838; (e) Chauhan, P.; Chimni, S. S. Asymmetric Addition of Indoles to Isatins Catalysed by Bifunctional Modified Cinchona Alkaloid Catalysts. Chem. - A Eur. J. 2010, 16, 7709-7713.

(19) (a) Lim, J. W.; Moon, H. R.; Kim, S. Y.; Kim, J. N. One-Pot Synthesis of Spirofluorenyl- and Spiroindeno[1,2-b]Indolyl Oxindoles via Sequential Interand Intramolecular Friedel-Crafts Reactions. Tetrahedron Lett. 2016, 57, 133-136; (b) Montesinos-Magraner, M.; Vila, C.; Cantón, R.; Blay, G.; Fernández, I.; Muñoz, M. C.; Pedro, J. R. Organocatalytic Asymmetric Addition of Naphthols and Electron-Rich Phenols to Isatin-Derived Ketimines: Highly Enantioselective Construction of Tetrasubstituted Stereocenters. Angew. Chemie Int. Ed. 2015, 54, 6320-6324; (c) Kaur, J.; Kumar, A.; Chimni, S. S. Organocatalytic Asymmetric Friedel-Crafts Reaction of 1-Naphthols with Isatins: An Enantioselective Synthesis of 3-Aryl-3-Hydroxy-2-Oxindoles. Tetrahedron Lett. 2014, 55, 2138-2141.

(20) (a) Shi, X.-L.; Lin, H.; Li, P.; Zhang, W. Friedel-Crafts Alkylation of Indoles Exclusively in Water Catalyzed by Ionic Liquid Supported on a Polyacrylonitrile Fiber: A Simple "Release and Catch" Catalyst. ChemCatChem 2014, 6, 2947-2953. (b) Brahmachari, G.; Banerjee, B. Facile and One-Pot Access of 3,3-Bis(Indol-3-Yl)Indolin-2-Ones and 2,2-Bis(Indol-3-Yl)Acenaphthylen-1(2H)-One Derivatives via an Eco-Friendly Pseudo-Multicomponent Reaction at Room Temperature Using Sulfamic Acid as an Organo-Catalyst. ACS Sustain. Chem. Eng. 2014, 2, 2802-2812. (c) Wang, Y.; Sang, R.; Zheng, Y.; Guo, L.; Guan, M.; Wu, Y. Graphene Oxide: An Efficient Recyclable Solid Acid for the Synthesis of Bis(Indolyl)Methanes from Aldehydes and Indoles in Water. Catal. Commun. 2017, 89, 138-142. (d) Tong, J.; Huang, L.-S.; Xu, D.-Z. An Efficient Friedel-Crafts Alkylation for the Synthesis of 3-Indolyl-3Hydroxy Oxindoles and Unsymmetrical 3,3-Diaryl Oxindoles Catalyzed by Dabco-Based Ionic Liquids in Water. New J. Chem. 2017, 41, 3966-3974. (e) Nagaraju, S.; Sathish, K.; Paplal, B.; Satyanarayana, N.; Kashinath, D. 3-Hydroxy-3-((3-Methyl-4-Nitroisoxazol-5-Yl)Methyl)Indolin-2-One as a Versatile Intermediate for Retro-Henry and Friedel-Crafts Alkylation Reactions in Aqueous Medium. New J. Chem. 2019, 43, 14045-14050. (f) Cheng, Y.; Ou, X.; Ma, J.; Sun, L.; Ma, Z.-H. A New Amphiphilic Brønsted Acid as Catalyst for the Friedel-Crafts Reactions of Indoles in Water.mono European J. Org. Chem. 2019, 2019, 66-72. (g) Pillaiyar, T.; Sedaghati, M.; Schnakenburg, G. Reaction of Indoles with Aromatic Fluoromethyl Ketones: An Efficient Synthesis of Trifluoromethyl(Indolyl)Phenylmethanols Using K2CO3/n-Bu4PBr in Water. Beilstein J. Org. Chem. 2020, 16, 778-790. (h) Singh, A.; Kaur, G.; Kaur, A.; Banerjee*, V. K. G. and B. A General Method for the Synthesis of 3,3-Bis(Indol-3-Yl)Indolin-2-Ones, Bis(Indol-3-Yl)(Aryl)Methanes and Tris(Indol-3Yl)Methanes Using Naturally Occurring Mandelic Acid as an Efficient Organo-Catalyst in Aqueous Ethanol at Room Temperature. Current Green Chemistry. 2020, 7, 128-140.

(21) (a) Gomes, J. C.; Sirvent, J.; Moyano, A.; Rodrigues, M. T.; Coelho, F. Aqueous Morita-Baylis-Hillman Reaction of Unprotected Isatins with Cyclic Enones. Org. Lett. 2013, 15, 5838-5841; (b) Gomes, J. C.; Rodrigues, M. T.; Moyano, A.; Coelho, F. Efficient Catalysis of Aqueous Morita-Baylis-Hillman Reactions of Cyclic Enones by a Bicyclic Imidazolyl Alcohol. European J. Org. Chem. 2012, 6861-6866.

(22) (a) Zhao, J.; Fung, B. M. NMR Study of the Transformation of Sodium Dodecyl Sulfate Micelles. Langmuir 1993, 9, 1228-1231. (b) Tang, X.; Koenig, P. H.; Larson, R. G. Molecular Dynamics Simulations of Sodium Dodecyl Sulfate Micelles in Water-The Effect of the Force Field. J. Phys. Chem. B 2014, $118,3864-3880$.

(23) Apparentlty, the reaction was strongly associated with the surfactant concentration, and values above the CMC were dentrimental to reaction selectivity. We believe that the increase of micelles (hydrophobic regions) potentialize the interaction of the mono-addition product with the other reactants what leads 
to the appear of byproducts.

(24) Selected examples of synthesis of disubstitued oxindoles under Brønsted acid catalysis: (a) Sharma, N.; Peddinti, R. K. Experimental and Theoretical Investigations of Regioselective Functionalization of 3-Hydroxy Bisindoles with Thiols. Org. Biomol. Chem. 2018, 16, 9259-9268; (b) Zhuo, M.-H.; Liu, G.-F.; Song, S.-L.; An, D.; Gao, J.; Zheng, L.; Zhang, S. Chiral Imidodiphosphoric Acids-Catalyzed Friedel-Crafts Reactions of Indoles/Pyrroles with 3Hydroxy-Indolyloxindoles: Enantioselective Synthesis of 3,3-Diaryloxindoles. Adv. Synth. Catal. 2016, 358, 808-815; (c) Wang, X.; Liu, J.; Xu, L.; Hao, Z.; Wang, L.; Xiao, J. Friedel-Crafts Alkylation of Heteroarenes and Arenes with Indolyl Alcohols for Construction of 3,3-Disubstituted Oxindoles. RSC Adv. 2015, 5, 101713-101717; (d) Zhou, L.-J.; Zhang, Y.-C.; Zhao, J.-J.; Shi, F.; Tu, S.-J. Organocatalytic Arylation of 3-Indolylmethanols via Chemo- and Regiospecific C6-Functionalization of Indoles. J. Org. Chem. 2014, 79, 10390-10398; (e) Sai Prathima, P.; Rajesh, P.; Venkateswara Rao, J.; Sai Kailash, U.; Sridhar, B.; Mohan Rao, M. “On Water” Expedient Synthesis of 3-Indolyl-3-Hydroxy Oxindole Derivatives and Their Anticancer Activity in Vitro. Eur. J. Med. Chem. 2014, 84, 155-159. 